\title{
MELHORIAS EM UMA EMPRESA DE EMBALAGENS DE MADEIRA ATRAVÉS DA UTILIZAÇÃO DA CRONOANÁLISE E REARRANJO DE LAYOUT
}

\author{
Nicolle Christine Sotsek $^{1 *}$, Ghislaine Miranda Bonduelle ${ }^{2}$ \\ ${ }^{1}$ Universidade Federal do Paraná, Departamento de Engenharia de Produção, Curitiba, Paraná, Brasil - *nicollesotsek@yahoo.com.br \\ ${ }^{2}$ Universidade Federal do Paraná, Departamento de Engenharia e Tecnologia Florestal, Curitiba, Paraná, Brasil - \\ ghislainebonduellemiranda @gmail.com \\ Recebido para publicação: 22/09/2014 - Aceito para publicação: 30/09/2016
}

\begin{abstract}
Resumo
Este trabalho teve por objetivo, desenvolver propostas de melhorias através da cronoanálise e modificações de arranjo físico, layout, do setor de montagem de uma empresa de embalagens de madeira no estado do Paraná, visando melhorar a eficiência produtiva desta linha de produção. A metodologia utilizada foi do tipo pesquisa-ação onde foram aplicados métodos de diagnóstico para análise da situação encontrada, passando pelo uso de ferramentas até chegar a um estado considerado como de melhoria. Os dados foram coletados através de observações efetuadas no processo, as quais verificaram, principalmente, os problemas organizacionais, o fluxo produtivo e a cronoanálise inicial. Com auxílio da equipe de produção, foram efetuados ensaios e aplicadas ferramentas de gestão, entre elas, o brainstorming, para se chegar ao melhor arranjo físico do setor. Os resultados mostraram uma melhoria no processo produtivo, com uma redução dos tempos em torno de $29 \%$ para o produto A e $33 \%$ para produto $\mathrm{B}$, reduções do espaço físico, e ainda conseguiu-se aprimorar a forma de trabalho da equipe, com a melhor organização espacial dos postos de trabalho e dos instrumentos de trabalho criados na fabricação do produto B houve um aumento de $66,67 \%$ no ritmo da produção, redução em mais de $50 \%$ do espaço e número de pessoas necessários para a montagem das embalagens, além de redução da fadiga das pessoas em 13\%. Conclui-se que a organização de um arranjo físico é fundamental para a melhoria da organização espacial, dos aspectos ergonômicos e do aumento da produtividade dentro da organização.

Palavras-chave: Arranjo físico; setor madeireiro; ganhos produtivos.
\end{abstract}

\begin{abstract}
Improvements in wood packaging a company though the chronoanalysis and layout rearrangement. This study aimed to develop proposals for improvements through the chronoanalysis and physical layout modifications, layout, mounting sector of a wooden packaging company in the State of Paraná, to improve the production efficiency of this production line. The methodology used was the type action research which was applied diagnostic methods for analysis of the situation encountered, through the use of tools to reach a state considered as improvement. Data were collected through observations made in the process, which occurred mainly organizational problems, the production flow and the initial chronoanalysis. With the help of the production team were carried out tests and applied management tools, including the brainstorming, to get the best physical sector arrangement. The results showed an improvement in the production process, with a reduction in time to around $29 \%$ for product $\mathrm{A}$ and $33 \%$ to product $\mathrm{B}$, physical space reduction, and still managed to improve the way of team work, with better spatial organization of jobs and working instruments created in B product manufacturing increased by $66.67 \%$ in the pace of production, reduction of more than $50 \%$ of the space and number of people required for assembly of packaging, in addition to reduction of fatigue of the persons $13 \%$. It follows that the organization of a physical arrangement is critical to improving the spatial organization, ergonomics and increased productivity within the organization.

Keywords: Physical arrangement; timber industry; productivity gains.
\end{abstract}

\section{INTRODUÇÃO}

Empresas de grande e pequeno porte vêm a cada dia um problema crescente, os chamados desperdícios ou perdas produtivas que estão presentes nos mais diversos processos industriais. Esses, por sua vez, podem ser causados por inúmeros fatores, interferindo na qualidade e na gestão de produção. $\mathrm{O}$ setor madeireiro, em específico, enfrenta um agravante a mais, a matéria-prima. A madeira, por ser um material heterogêneo, acaba se tornando um grande desafio para as indústrias, pois muitos dos processos padronizados precisam ser adaptados

FLOREST A, Curitiba, PR, v. 46, n. 4, p. 519 - 530, out. / dez. 2016.

Sotsek, N. C.; Bonduelle, G. M.

ISSN eletrônico 1982-4688

DOI: $10.5380 /$ rf.v46i.37886 
para se alcançar o máximo de aproveitamento da matéria-prima. As principais perdas de um processo podem estar relacionadas com: os equipamentos ineficientes, matéria- prima de baixa qualidade, despreparo da equipe, tempos improdutivos e, também, com a disposição do estoque e dos maquinários na produção.

Este último fator que é chamado de arranjo físico, ou também de layout, é um tema bastante abordado atualmente, pois interfere em toda a cadeia produtiva e pode trazer resultados positivos com alta significância.

A aplicação de técnicas de estudo de sistemas em ambientes industriais é cada vez mais significativa devido às modificações e necessidades de produção exigidas. Segundo Freitas et al. (2008) um layout bem estudado e estruturado pode proporcionar grandes vantagens, são elas: aumento da flexibilidade do processo, da produção, redução do estoque no processo, das áreas desnecessárias, redução da movimentação de materiais, entre tantas outras.

A indústria madeireira no Brasil é caracterizada por altos índices de desperdício. As perdas podem chegar até $70 \%$ do volume de madeira em tora consumida (OLANDOSKI, 2001). Estudos de layout, para otimização de processo, foram conduzidos por Mazieiro et al. (2013) em uma serraria objetivando melhorar a disposição dos equipamentos e a qualidade de trabalho dos funcionários. Boa et al. (2012) analisaram o caso de uma moveleira e propuseram como solução para redução de resíduos um novo layout industrial. Garcia (2012) também estudou uma movelaria e, através de simulação, propôs um layout mais adequado à empresa. Como resultado ele obteve a redução de tempo e do espaço produtivo, e aumento da produtividade.

A empresa estudada neste trabalho apresentava uma série de problemas produtivos que estavam ligados diretamente com o arranjo físico, tais como: grande movimentação da equipe e da matéria-prima, alto nível de estresse da equipe, falta de organização dos produtos acabados e semiacabados, equipamentos fora do lugar, entre outros.

Considerando o exposto, esta pesquisa tem por objetivo principal otimizar o setor de embalagens de madeira destinadas ao setor automotivo, na região de Curitiba, através da cronoanálise e do rearranjo do layout deste setor, visando à redução de desperdícios na linha produtiva.

Desta forma, a expectativa do estudo é que o setor diminua suas perdas de tempo por deslocamento de produtos e pessoas, além da redução do cansaço físico excessivo da equipe durante a jornada de trabalho.

\section{REVISÃO DE LITERATURA}

\section{Arranjo físico ou layout}

Segundo Vieira (1979), Muther (1986) e Slack et al. (2002) o arranjo físico, ou também chamado layout, é a relação entre a disposição dos homens, dos equipamentos e maquinários em uma fábrica. A interação entre esses elementos dá forma ao processo e molda o fluxo dos recursos ao longo das operações. Sendo assim, o layout de uma empresa deve ser um espaço bem organizado para gerar o menor tempo de produção, as melhores condições de trabalho e a menor movimentação de materiais, produtos e pessoas.

Algumas vantagens de um bom layout são destacadas por Vieira (1979), as quais se resumem em ambiente de trabalho com menor risco para saúde e segurança dos colaboradores, maior produtividade em um tempo menor, redução dos manuseios e espaços percorridos, economia no espaço, produção mais rápida, fácil supervisão, menores danos ao material e a sua qualidade, e ajuste mais fácil à mudanças.

Rawabdeh e Tahboub (2005) relatam que o layout é um dos aspectos mais importante a se analisar dentro da manufatura, porque requer planejamento a longo prazo em virtude da sua complexidade e dos altos custos financeiros, relacionados com a adaptação dos equipamentos, dos maquinários, da equipe e de todo o processo dentro de uma organização. Os autores destacam ainda, que o layout afeta a produtividade, o desempenho da fábrica, o espaço utilizado, a mão de obra eficiente e ainda a motivação dos colaboradores.

\section{Fatores que influenciam no arranjo físico}

Durante a organização do layout é de extrema importância levar em conta os fatores presentes na estrutura de trabalho. Eles são essenciais na hora de uma mudança e podem variar de uma empresa para outra. De acordo com Rocha (1995) os principais fatores são:

- Transporte interno, tanto das partes fixas como as esteiras ou das partes moveis como as empilhadeiras. Elas devem ser levadas em consideração devido ao dimensionamento;

- A matéria prima e o produto, também devido ao dimensionamento;

- A equipe de trabalho (homem), devido ao contínuo movimento durante as atividades e monitoramento dos processos;

- Os equipamentos e maquinários, devido a sua capacidade produtiva e eficiência que poderão ser influenciados pelo espaço físico utilizado.

De acordo com Silva (2009), existem diversas formas de se posicionar os recursos físicos no chão de fábrica, e cada uma destas formas traz vantagens e desvantagens. A seguir serão apresentados os modelos mais tradicionais, sendo eles: Arranjo Funcional, em Linha e Celular. 


\section{Arranjo Funcional (ou Arranjo em Processo)}

O Arranjo Funcional foi à primeira forma lógica de disposição utilizada para alocar os recursos físicos dentro de uma fábrica (SILVA, 2009). Este arranjo é organizado de maneira que os sistemas semelhantes fiquem próximos uns dos outros de forma que as máquinas sejam agrupadas por funções (setor de corte, setor de usinagem, etc.) em locais fixos, e as peças são movimentadas pela fábrica (ROCHA, 2011).

Segundo Rocha (2011), as principais vantagens deste arranjo são a grande flexibilidade para atender o mercado, o fato de que atendem produtos variados e em quantidade variável e o menor investimento industrial. Em contrapartida, apresenta como desvantagens fluxo longo dentro da fábrica, pouco monitoramento e exige mão de obra qualificada.

\section{Arranjo em Linha (ou Arranjo por Produto)}

De acordo com Viera (1979), o layout linear é aquele em que as máquinas são arranjadas de acordo com a sequência de operações a serem realizadas. Este layout, segundo Silva (2009), foi popularizado pela linha de montagem criada por Henry Ford.

Dentre suas vantagens destacam-se a grande produtividade em massa, utilização de fluxo contínuo e o fácil monitoramento das atividades. Por outro lado, apresentam as desvantagens de alto investimento em maquinários e a geração de tédio na equipe de trabalho.

\section{Arranjo Celular}

O layout Celular é composto por um agrupamento de máquinas que geram as chamadas células, que funcionam de maneira bastante similar a uma linha de produção dentro de um layout por processo (GAITHER; FRAZIER, 2002).

As principais vantagens deste tipo de arranjo são a redução de espaço, a flexibilidade quanto ao tamanho do lote, a supervisão e programação da manufatura simplificada e racional e a redução de estoques. Como desvantagens cita-se a dificuldade em elaborar o arranjo, e o arranjo específico para famílias de produtos.

Para Slack et al. (2002) as decisões de um arranjo físico são muito importantes, pois podem refletir diretamente no desempenho da empresa e na satisfação dos seus clientes.

\section{Ferramentas de análise}

Cronoanálise

O principal objetivo da cronoanálise é realizar as atividades durante a fabricação de produtos e peças, de forma a possibilitar a quantidade de tempo que está sendo efetivamente utilizado em tarefas que efetivamente agregam valor ao processo.

Dada esta definição, pode-se notar já de início que a cronoanálise possui uma grande importância, pois através dela é possível balancear uma linha de montagem, ou de produção, tendo como base a medição dos tempos necessários para cumprir cada uma das atividades que fazem parte do processo (CRONOANÁLISE INDUSTRIAL, 2016).

Segundo Michelino (1964) um Estudo de Tempos é composto por quatro fases, sendo elas:

1.Preliminares: consiste em entrar em contato com o ambiente de trabalho, identificar a operação, verificar o material e o equipamento e anotar a data e hora do estudo;

2. Análises da Operação: esta fase engloba as seguintes atividades: descrever a operação em seu conjunto; verificar as condições de trabalho; traçar o croqui do lugar de trabalho; descrever os elementos da operação; e, criticar o método usado.

3. Cronometragem: esta etapa consiste em definir os pontos de leitura, ler e anotar os tempos de vários ciclos sucessivos, tomar nota de qualquer irregularidade, avaliar e anotar a atividade do operador e anotar os coeficientes de fadiga.

4.Cálculos: esta fase é composta das seguintes atividades: eliminar erros e irregularidades; calcular as médias das atividades e dos tempos; normalizar os tempos médios; calcular os tempos-base; determinar o tempo-base do ciclo por unidade; determinar as tolerâncias para demora; e, calcular o tempo-padrão por unidade.

\section{Brainstorming}

Segundo Kotler (1980) trata-se de uma técnica capaz de produzir um conjunto de ideias. Esta pode ser realizada com um grupo em torno de seis a dez pessoas, especialistas no assunto, os quais irão discutir a respeito de um tema com objetivo de gerar ideias durante um período de mais ou menos uma hora. O brainstorming é organizado a partir de um líder que conduz o início da atividade, e em seguida, as ideias vão surgindo e sendo expostas, umas após as outras. Para que a reunião seja eficiente Osborn citado por Kotler (1980), fundador da técnica apresenta quatro regras para uma boa conduta: 
- Proibição de críticas: opiniões contrárias devem ser guardadas para mais tarde;

- A liberdade de ideias é bem-vinda: quanto mais fantástica melhor;

- A quantidade é desejada: quanto mais ideias melhor.

\section{MATERIAL E MÉTODO}

O estudo foi conduzido em uma empresa de embalagens de madeira localizada na região metropolitana de Curitiba, PR. Esta empresa organiza suas atividades em duas grandes linhas:

1.Preparação da madeira: processo que envolve todo o beneficiamento da madeira, como corte, furação, aplainamento, entre outros.

2. Montagem das Embalagens e Pallets: as peças de madeira cortadas nas medidas devidamente estabelecidas são encaminhadas para este setor que possui a função de unir as peças para produção da embalagem de madeira. Esta união é feita a partir de um equipamento pneumático, que através da alta pressão libera os pregos, fixando-os na madeira.

O setor de Montagem de Embalagens em Madeira é o setor estudado neste trabalho, no qual as peças de madeira montadas para a fabricação denominam-se de: Cabeceira, Lateral, Tampa e Base.

Para reorganização do layout, dois produtos foram escolhidos para o estudo, em função da sua alta participação financeira e produtiva, e serão denominados como: produto A e produto B ao longo desta pesquisa.

A metodologia aplicada neste trabalho está organizada em três etapas principais (Figura 1).

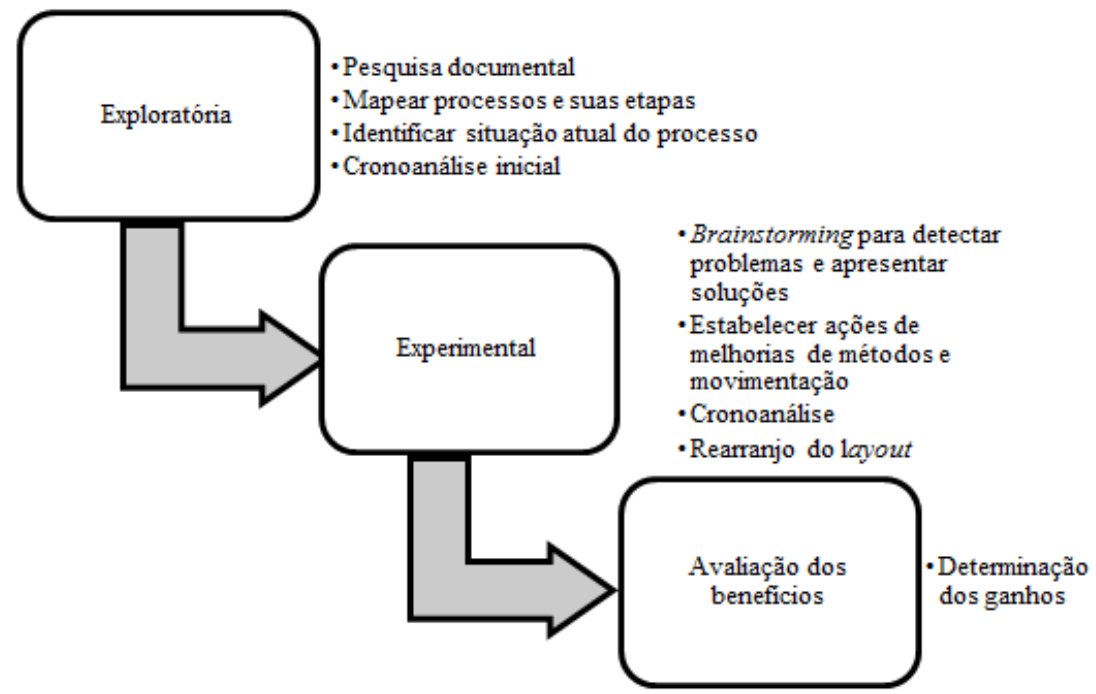

Figura 1. Representação esquemática da metodologia aplicada.

Figure 1. Schematic representation of the methodology applied.

\section{Etapa exploratória}

A etapa exploratória é a fase do estudo preliminar, onde os pesquisadores se familiarizam com o caso estudado e formulam as possíveis hipóteses de pesquisa (GIL, 2008). Nesta etapa são efetuados os seguintes procedimentos:

- Pesquisa documental: busca através da literatura estudos para embasar suas hipóteses;

- Observações e anotações a respeito da dinâmica da atividade produtiva dentro do setor;

- Coleta preliminar de dados de tempos produtivos para entrar em contato com o ambiente de trabalho, identificar a operação, verificar o material e o equipamento e anotar a data e hora do estudo (MICHELINO, 1984).

Com as informações e dados coletados a respeito do caso estudado, concluiu-se que um novo layout deveria ser proposto a fim de corrigir os problemas detectados. Assim, passou-se para a fase experimental.

\section{Etapa experimental}

Nos procedimentos 1 e 2, listados a seguir, foi aplicada a ferramenta brainstorming que consiste em discutir objetivos a serem atingidos com a equipe de trabalho. Em cada reunião o objetivo a ser atingido era 
exposto pelo coordenador da reunião e foram estabelecidos os tempos de até 10 minutos para a fase de geração e ideias e até 20 minutos para a exploração e ideias

1. Realizações de reuniões com a equipe de trabalho do setor para mapeamento do processo, discussão dos principais problemas que o layout atual trazia ao processo, entre eles, organização dos espaços, movimentação da matéria-prima, produtos acabados, produtos utilizados, etc.

2. Identificação de oportunidades de melhoria no processo, elaborando um novo layout ao setor.

3. Utilização da ferramenta cronoanálise com objetivo de identificar os tempos médios de montagem de cada produto em linha. Segundo Seleme (2009) o estudo de tempos na indústria permite a empresa organizar de forma eficiente seu sistema produtivo o que permite estabelecer valores confiáveis em termos de quantidade a ser produzida e de custos de produção. Nesta pesquisa foram levantados os tempos padrões, através da observação da execução dos procedimentos e do cronometro digital.

Etapa avaliação de benefícios

A última etapa buscou-se como o próprio nome diz avaliar os benefícios identificados através das melhorias propostas, de forma que sejam determinados os ganhos do sistema de produção.

\section{RESULTADOS E DISCUSSÕES}

A partir da ferramenta brainstorming e das reuniões realizadas, foram detectados os principais problemas no setor, bem como as soluções propostas através das reuniões estabelecidas com os funcionários do setor e com base no que a literatura traz como princípios. Estes resultados estão resumidos na figura 2.

\begin{tabular}{|l|l|l|}
\hline Situação Detectada & Descrição & Possíveis soluções \\
\hline Fabricação ineficiente Produto B & Problemas ergonômicos: desgaste físico excessivo; & $\begin{array}{l}\text { Desenvolver um novo método para fabricação } \\
\text { deste produto }\end{array}$ \\
\hline $\begin{array}{l}\text { Desperdício de tempo na coleta de } \\
\text { matéria-prima }\end{array}$ & $\begin{array}{l}\text { Não existe um espaço adequado para estoque de matéria-prima cada } \\
\text { vez que a fabricação de um novo produto inicia. Portanto, os } \\
\text { colaboradores precisam procurar estes recursos pelo setor gerando } \\
\text { tempos improdutivos e desnecessários; }\end{array}$ & $\begin{array}{l}\text { Criação de um local específico para a matéria- } \\
\text { prima }\end{array}$ \\
\hline $\begin{array}{l}\text { Falta de espaço para fabricação dos } \\
\text { produtos }\end{array}$ & $\begin{array}{l}\text { O setor não possui áreas delimitadas para fabricação, por isso muitas } \\
\text { vezes falta espaço para produzir e estocar material; }\end{array}$ & $\begin{array}{l}\text { Criar um local específico para fabricação dos } \\
\text { produtos e para estocagem do produto final }\end{array}$ \\
\hline $\begin{array}{l}\text { Produto A e B são os mais } \\
\text { importantes no setor }\end{array}$ & $\begin{array}{l}\text { É preciso criar um método mais adequado para aperfeiçoar o processo } \\
\text { de fabricação destes dois produtos. Eles não têm uma sequência } \\
\text { lógica de processo; }\end{array}$ & $\begin{array}{l}\text { Elaboração de um layout específico para estes } \\
\text { dois produtos }\end{array}$ \\
\hline
\end{tabular}

Figura 2. Principais problemas detectados no setor.

Figure 2. Main problems detected in the sector.

Em geral, pôde-se perceber que o principal problema do setor de montagem está na disposição dos postos de trabalho e dos equipamentos e matéria-prima utilizada no setor. Assim, através das situações detectadas, foi possível estabelecer as seguintes atividades de melhorias:

1. Reorganização do layout do setor;

2.Elaboração do layout para os produtos A e produto B;

3. Melhorar a fabricação do produto B.

Melhoria 1: Processo de reorganização do layout no setor de montagem de embalagens em madeira

Mudanças no processo produtivo sempre geram um tipo de desconforto para a equipe de trabalho. Por isso, essa ação pode, e deve ser realizada em conjunto com a equipe de produção, a qual deve ser treinada e incentivada para buscar sempre mudanças para melhoria no processo produtivo. Neste item serão apresentadas as situações onde foram detectadas oportunidades de melhorias e as ações implantadas para a reorganização do layout:

Problema: excesso de desperdícios de tempo no setor

A partir das observações efetuadas no setor e de reuniões realizadas com a equipe de trabalho, foi detectado que o arranjo do setor gerava desperdícios de tempo ao longo do processo. Uma primeira situação proporcionou essa conclusão: $\mathrm{O}$ espaço de trabalho não apresentava áreas definidas com uma delimitação clara

FLOREST A, Curitiba, PR, v. 46, n. 4, p. 519 - 530, out. / dez. 2016.

Sotsek, N. C.; Bonduelle, G. M.

ISSN eletrônico 1982-4688

DOI: $10.5380 /$ rf.v46i.37886 
das regiões. Esta situação pode ser exemplificada com a região de estoque de matéria-prima, dos postos de trabalho, e da zona de montagem, as quais não possuíam uma delimitação para cada região, existindo apenas um espaço único chamado setor de montagem. Assim, cada vez que um processo era efetuado ele acabava sendo realizado em diferentes postos de trabalho que estavam localizados nos mais diversas regiões dentro do setor.

Em seguida, cada parte da embalagem (constituída de: Cabeceira, Tampa, Lateral e Base) era produzida em um posto de trabalho. Seguindo o fluxo, todas as peças eram deslocadas, através de palleteiras para outra região, onde se efetuava o processo de montagem final da embalagem. Neste segundo local, o produto agora montado era deslocado uma terceira vez, para outra região onde seria expedido. Essas atividades, por sua, vez geravam as perdas de tempo por deslocamento, desorganizações no processo, fadiga nos operários e, ainda, impediam um melhor monitoramento no processo.

\section{Melhoria Proposta}

Como cada produto é único no setor de montagem, o arranjo físico nunca será o mesmo, ele poderá sofrer modificações dependendo da embalagem produzida. Por isso, novamente chama-se a atenção da importância de desenvolver a organização do arranjo físico em conjunto com a equipe do setor, para que possase criar um hábito de forçar os funcionários a pensar como deve ser feita a organização do espaço para a fabricação, e fazer isto toda vez que um novo produto for inserido na linha de produção. O ideal neste caso seria a realização das embalagens em um fluxo contínuo, para facilitar o processo de montagem e evitar as perdas de tempo. E como existe uma variedade peças e etapas, seria interessante criar células de trabalho para aperfeiçoamento do processo.

\section{Resultado após a implantação da melhoria}

Neste caso, os postos de trabalho foram arranjados em uma sequência ou em uma área específica para realização da montagem das embalagens, e foi obtido:

- Um mínimo de estoque acessível para montagem;

- Um local de estoque de produtos acabados próximos das portas para fazer a expedição;

- Um local de montagem próximo tanto do mercado de matéria-prima como da expedição.

Após a organização do espaço, marcações foram feitas no solo para delimitar as áreas que foram divididas conforme abaixo, as quais podem ser visualizadas na figura 3 :

- Mercado: estoque de matéria-prima;

- Expedição: estoque de produto finalizado;

- Montagem: produto em processo e região de circulação da equipe de trabalho

- Produto cliente: área de estoque de produtos dos clientes.

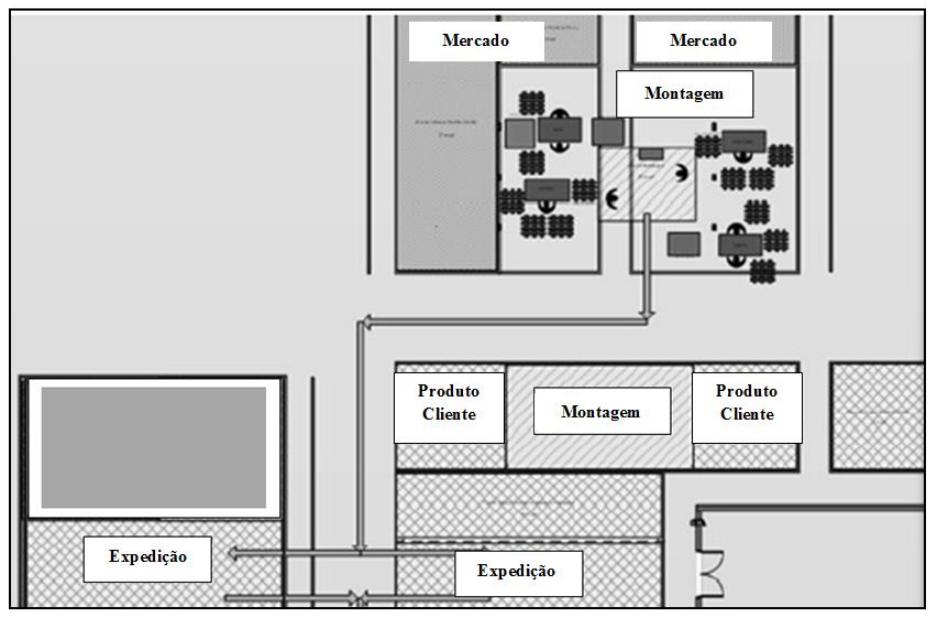

Figura 3. Delimitação dos espaços do layout do setor de Montagem.

Figure 3. Delimitation of layout spaces of Montage sector.

Neste período, foi realizada uma série de simulações com o novo layout para verificar em que local estaria a melhor forma de montagem das embalagens. Com esse novo sistema foram obtidas as seguintes vantagens:

- Fluxo produtivo mais visual. Com as áreas delimitadas, sabe-se o que está acontecendo em cada espaço do processo, facilitando o controle da atividade; 
- A matéria-prima estocada está localizada na área denominada "mercado". Este local é estratégico, pois se situa entre o setor que preparação do material e o setor de montagem do produto.

- O local de estoque de produto acabado "expedição" foi localizado na porta de entrada/saída.

- A zona de montagem ficou com livre acesso para circulação da equipe, enquanto a matéria-prima está localizada na zona mercado, o que facilita a movimentação e a organização do setor.

- Os corredores de acesso foram sinalizados para auxiliar no transporte dos produtos e melhorar a segurança do trabalho.

Portanto, o layout mais adequado para este setor é o celular, que organiza suas atividades de acordo com a similaridade das atividades do processo.

O trabalho de Lima (2008) também identificou melhorias no processo produtivo após a organização do layout. $\mathrm{O}$ autor afirma que quando existe o planejamento físico de um setor isso resulta "em uma aplicação eficiente dos equipamentos e máquinas de produção, fluxos rápidos e maior controle e entendimento do processo produtivo". Pode-se, ainda, citar o trabalho de Favaretto et al. (2011) que mostra as vantagens obtidas através da organização do layout: a diminuição do lead time de produção de peças; aumento do valor agregado no material e, ainda, a redução ao máximo dos estoques intermediários.

\section{Melhoria 2: Elaboração de Layout específico para os produtos A e B}

Com o espaço físico já delimitado, aproveitou-se da experiência para a elaboração de um layout específico para os produtos A e B. Com ajuda da equipe produtiva, analisou-se o processo em estudo e os postos de trabalho foram organizados para melhorar o fluxo e assim impedir problemas relacionados o espaço físico.

\section{Melhoria proposta}

O novo arranjo organizou as bancadas dentro da zona de montagem. Estas bancadas são chamadas de postos de trabalho, nestes locais identificou-se a necessidade de criar um espaço para armazenagem de matéria prima em processo. Este arranjo referente à produção do produto $\mathrm{A}$, pode ser visualizado na figura 4 .

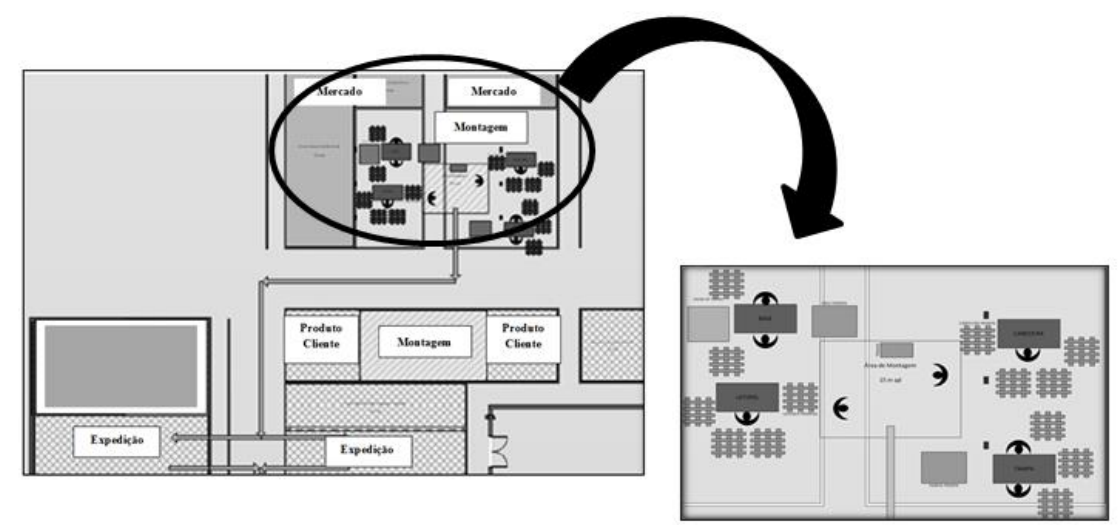

Figura 4. Layout do Produto A.

Figure 4. Layout of Product A.

A organização foi relativamente simples, a partir dos tempos necessários para a produção de cada peça da embalagem ordenaram-se os postos de trabalho permitindo que no final as peças terminassem próximas umas das outras, e relativamente juntas. Nesta fase, o treinamento também foi aplicado para que a equipe produtiva fizesse uma pequena análise da organização do processo, insistindo na criação de uma cultura organizacional dentro do setor de Montagem.

\section{Resultado após a implantação da melhoria}

A evolução da atividade foi verificada através da cronometragem dos tempos de produção. A tabela 1 mostra os tempos de produção antes e depois da organização do layout do produto A e o ganho obtido após essa organização. 
Tabela 1. Layout do Produto A.

Table 1. Layout of Product A.

\begin{tabular}{lll}
\hline Layout & Antes & Depois \\
\hline Distância média percorrida pelo operário & $759 \mathrm{~m}$ & $349 \mathrm{~m}$ \\
Tempo médio produção Tampa & $2,6 \mathrm{~min}$ & $1,7 \mathrm{~min}$ \\
Tempo médio produção Lateral & $1,6 \mathrm{~min}$ & $1,0 \mathrm{~min}$ \\
Tempo médio produção Cabeceira & $0,6 \mathrm{~min}$ & $0,5 \mathrm{~min}$ \\
Tempo médio produção Base & $3,5 \mathrm{~min}$ & $2,2 \mathrm{~min}$ \\
\hline
\end{tabular}

A tabela 2 mostra os tempos de produção, medidos com cronômetro, antes e depois da organização do layout.

Tabela 2. Tempos produtivos Cliente A.

Table 2. Productive time Client A.

\begin{tabular}{lccc}
\hline \multicolumn{4}{c}{ Cliente A - Produção 50 peças } \\
\hline Partes da Embalagem & Tempo antes (s) & Tempo depois (s) & \% \\
\hline Tampa & 8013 & 5165 & 65 \\
Lateral & 4817 & 3110,4 & 65 \\
Base & 10612 & 6695 & 63 \\
Cabeceira & 1910 & 1588 & 83 \\
Cantoneira & 3000 & 3000 & 0 \\
\hline Total (segundos) & 28029 & 19880 & 7 \\
Total (minutos) & 467 & 331 & 71 \\
Total (horas) & 8 & 6 & 75 \\
\hline
\end{tabular}

O layout do cliente A apresentou os seguintes benefícios:

- Fluxo produtivo ficou mais visível, pois cada posto de trabalho produz um tipo de peça, evitando problemas organizacionais;

- Ganho produtivo;

- Os postos de trabalho tornaram-se mais organizados. Cada um apresenta sua estrutura e organiza suas tarefas de acordo com a peça que está sendo fabricada evitando perdas por movimentação e transporte;

- Cada posto de trabalho apresenta um estoque regulador mínimo de matéria-prima, evitando deslocamentos desnecessários;

- A montagem do produto ficou localizada em um único espaço físico (centro do processo).

Cliente B:

O layout do cliente B foi organizado junto com uma nova proposta de gabarito, que proporcionou benefícios significativos. O layout do cliente $\mathrm{B}$, antes do gabarito, pode ser visto na figura 5 .

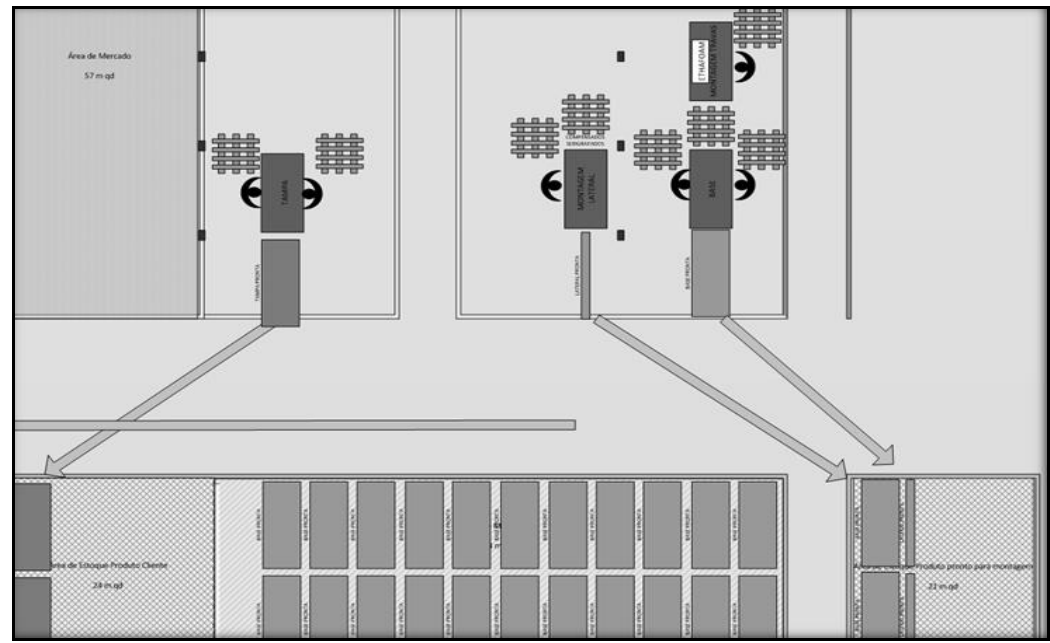

Figura 5. Layout do Cliente B antes da implantação de melhorias.

Figure 5. Layout of Client B before the implementation of improvements. 
O layout do cliente B apresentava as seguintes características negativas:

- Grande utilização do espaço produtivo, cerca de toda a área de montagem era utilizada só para esse cliente em específico;

- Grande deslocamento da equipe de trabalho;

- Difícil monitoramento da atividade;

- Diminuição do trabalho efetuado no chão de fábrica, gerando dores musculares;

- Redução da fadiga excessiva devido ao deslocamento desnecessário e forma de trabalho incorreta.

A partir das observações feitas durante o processo de montagem das embalagens e das reuniões com a equipe produtiva, buscou-se desenvolver um ambiente mais ergonômico para a equipe de trabalho.

\section{Melhoria 3: Melhorias na ergonomia do processo do produto $B$}

A montagem das embalagens era realizada no chão de fábrica, através de um movimento fatigante de levantar e abaixar. Esse tipo de manuseio gera uma movimentação continua das partes do corpo humano e, por consequência, a fadiga dos músculos e o cansaço excessivo do funcionário. Esse tipo de situação além de reduzir a eficiência do trabalhador pode gerar acidentes de trabalho.

\section{Melhoria proposta}

Para evitar essa fadiga, o recurso desenvolvido foi criar um gabarito diferenciado, o qual pudesse ser transportado de um local a outro, e ainda, fosse utilizado em cima das bancadas evitando, portanto, a montagem no chão de fábrica. A figura 6 mostra a atividade.
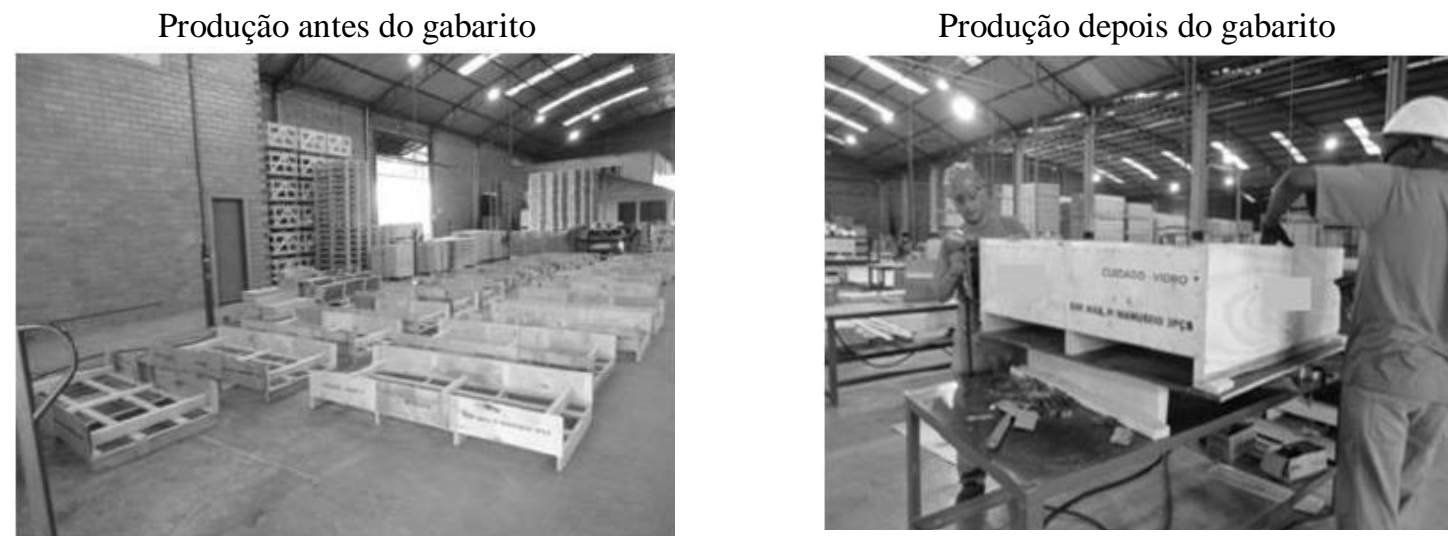

Figura 6. Processos de montagem das embalagens do Produto B.

Figure 6. Mounting process packaging of Product B.

O gabarito foi feito com material reciclado e com as ferramentas que a própria empresa possuía. Ele tem as dimensões exatas para a produção das embalagens do produto B. Na figura 6 pode-se observar que as embalagens eram produzidas no chão de fábrica e ocupavam um espaço muito grande, às vezes até os corredores eram utilizados.

Resultados após a implantação da melhoria:

Com o a utilização do gabarito (Figura 6), a produção deste mesmo produto foi efetuada em uma única bancada, o que reduziu o espaço físico da produção e melhorou a ergonomia no posto de trabalho.

A postura na hora de trabalhar é fundamental. Por isso, valorizou-se essa necessidade e criou-se um ambiente mais agradável e ergonômico para produção das embalagens. Com a melhoria, o trabalhador evita o movimento de inclinação do tronco, trocando essa operação por uma atividade com postura ereta. O novo layout do produto $\mathrm{B}$, a partir da implantação do gabarito pode ser visualizado na figura 7 .

O layout do produto B apresentou os seguintes benefícios:

- Redução do espaço físico para montagem das embalagens;

- Melhor organização das bancadas de trabalho;

- Fluxo produtivo mais visível com um maior controle de produção;

- Produção das embalagens mais eficiente, através do ganho em tempo produtivo e da melhoria dos aspectos ergonômicos na execução das tarefas. 


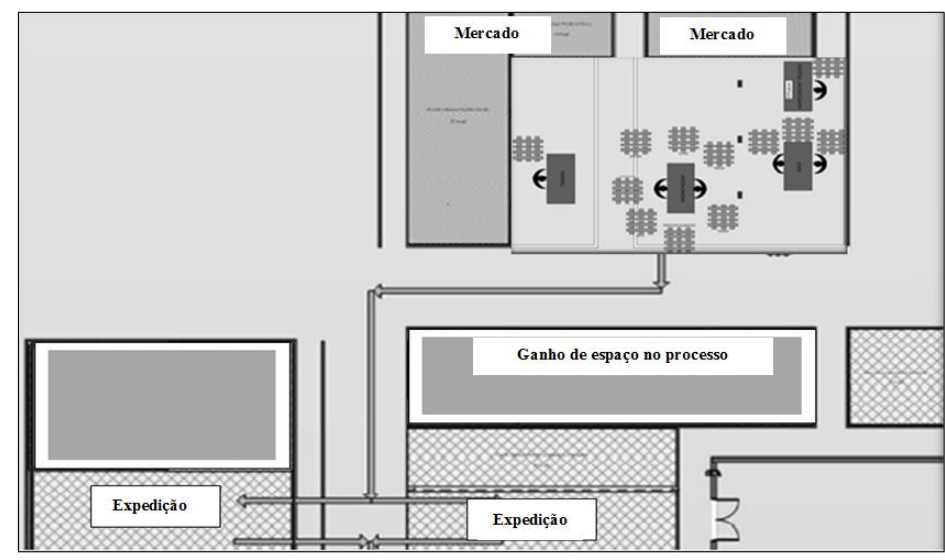

Figura 7. Layout do produto B após o gabarito.

Figure 7. Layout pf Product B after the template.

A partir da aplicação do gabarito no processo produtivo, obtiveram-se os seguintes resultados positivos, que podem ser vistos na tabela 3 .

Tabela 3. Montagem das embalagens do Produto B.

Table 3. Mounting of packaging of Product B.

\begin{tabular}{llll}
\hline Ações & Antes & Depois & Ganho \\
\hline Utilização do espaço físico & $15 \times 12 \mathrm{~m}$ & $5 \times 5 \mathrm{~m}$ & Redução de espaço físico \\
$\begin{array}{l}\text { Quantidade de pessoas necessárias para } \\
\text { realização da montagem }\end{array}$ & $4 \mathrm{a} 6$ & 2 & Pessoas \\
Fadiga & $27 \%$ & $14 \%$ & Ergonômico \\
Posição de trabalho & $\begin{array}{l}\text { Agachado e movimento de } \\
\text { abaixar e levantar continuamente }\end{array}$ & $\begin{array}{l}\text { Em pé } \\
\text { (vertical) }\end{array}$ & Ergonômico \\
Deslocamento & Contínuo & Nenhum & Ergonômico \\
Tempo de produção & 5,4 min & 3,6 min & Redução do tempo produtivo \\
\hline
\end{tabular}

A redução do tempo necessário para o trabalho reduz o estresse da equipe e aumenta a satisfação no trabalho, aumentando a produtividade das equipes conforme afirmação de Anton et al. (2012): "outros fatores importantes para remodelamento ou construção de novo layout, são a satisfação das pessoas no ambiente de trabalho e principalmente a agilidade no atendimento a seus clientes".

\section{CONCLUSÃO}

- A implantação de layouts específicos contribuiu para reduzir os desperdícios dentro do setor estudado.

- Através da cronoanálise, o tempo de montagem foi reduzido em torno de $29 \%$ para o Produto A, e em $33 \%$ para o produto B. Foi criado um arranjo específico para os clientes em estudo proporcionando melhorias na produção.

- O novo arranjo apresentou características de um layout Celular, com as seguintes melhorias: Adaptação de cada posto de trabalho de acordo com a peça produzida; os produtos foram produzidos em células que finalizavam no centro do setor de montagem, facilitando o processo de encaixe das peças; Fácil percepção da falta de material localizada no sistema; Maior controle e monitoramento das atividades.

- O novo layout do produto B, permitiu que o ritmo de produção aumentasse em 66,67\% e os problemas ergonômicos fossem reduzidos na fabricação do produto B proporcionando um ambiente mais seguro e agradável para se trabalhar e foi obtida uma redução de $14 \%$ na fadiga das pessoas. A utilização do espaço físico para a montagem das embalagens e o número de pessoas necessárias para a montagem foram reduzidas para menos da metade.

- Conclui-se que a organização de um arranjo físico é fundamental para a melhoria da organização espacial, dos aspectos ergonômicos e do aumento da produtividade dentro da organização.

- Sem uma ferramenta estruturada para o planejamento e implantação das melhorias o trabalho pode ficar incompleto ou não atingir aos objetivos de melhoria esperados. 


\section{REFERENCIAS}

ANTON, C. I.; EIDELWEIN, H.; DIEDRICH, H. Proposta de Melhoria no Layout de produção de uma empresa no Vale do Taquari. Revista Destaque Acadêmicos, Lajeado, v. 14, n. 1, p. 129-148, 2012.

BOA, A. C.; DONATELLI J. S.; ANDRADE W. S. P.; NOGUEIRA M. A. Análise do Layout de uma indústria moveleira localizada no polo de Linhares. Floresta e Ambiente, Seropédica, v. 19, n. 2, p. 155-161, 2012.

CRONOANÁLISE INDUSTRIAL. Disponível em: http://www.gestaodeproducao.com.br/servicos/cronoanalise/ cronoanalise-industrial > acesso em: 21 de out de 2016.

FAVARETTO, P. V.; KUREK, J.; GOMES, A. J.; CAIBRE, D. I.; PANDOLFO, A. Projeto de Layout industrial para uma empresa do ramo metal- mecânico com base nos princípios da Produção Enxuta. Revista Ciência Exatas e Naturais, Irati, v. 13, n. 1, p. 45-71, 2011.

FREITAS, A. O.; OLAVE, M. E. L.; VIEIRA, R. K. Manufatura enxuta como ferramenta na mudança de layout do formato de "U" para o formato em "I". Um estudo de caso. In: XXVIII ENCONTRO NACIONAL DE ENGENHARIA DE PRODUÇÃO. Anais ENEGEP 2008. Editora ABEPRO: Rio de Janeiro 2008.

GAITHER, N.; FRAZIER, G. Administração da Produção e Operações. São Paulo: Ed. Pioneira, 2001.

GARCIA, G. O. Proposta de Melhoria de Layout Produtivo utilizando simulação computacional: estudo de caso em uma indústria do setor moveleiro. $80 \mathrm{f}$. Trabalho de conclusão de curso (Graduação em Engenharia de Produção)- Universidade da Amanôzina, Belem, 2012.

GIL, A. C. Como elaborar projetos de pesquisa. São Paulo: Atlas, 5 ed., 2008, 176 p.

KOTLER, P. Marketing. São Paulo: Atlas, 1980.

LIMA, F. A. J. Otimização e Reprojeto do layout através da sistemática de planejamento com base teórica: Um estudo de caso. 76 f. Dissertação (Bacharel em Engenharia) - Universidade do Estado de Santa Catarina, Florianópolis, 2008.

MAZIERO, R.; MAGNAGO, F. C.; PAULA, E. N. S. O.; FIEDLER, N. C.; PAULA, M. O. Otimização do Layout de uma serraria de Dores do Rio Preto, ES. Revista Científica Eletrônica de Engenharia Florestal, Garça, v. 22, n. 1, p. 50-61, 2013.

MICHELINO, G. Estudo de Tempos e Supervisores. 2. ed. São Paulo: Publicações Educacionais Limitada, 1964. $204 \mathrm{p}$.

MUTHER, R. Planejamento do Layout: Sistema SLP. São Paulo: Edgard Blucher, 1978, 224 p.

OLANDOSKI, D. P. Rendimento, resíduos e considerações sobre melhorias no processo em uma indústria de chapas compensadas. Dissertação (Mestrado em Ciências Florestais) - Universidade Federal do Paraná, Curitiba, 2001.

RAWABDEH, I.; TAHBOUB, K. A new heuristic approach for a computer-aided facility layout. Journal of Manufacturing Technology Management, Whashington, v. 17, n. 7, p. 962-986, 2005.

ROCHA, H. N. Apostila da disciplina: Arranjo Físico Industrial, Rio de Janeiro: Universidade do Estado do Rio de Janeiro. 2011, 84 p.

ROCHA, D. Fundamentos Técnicos da Produção. São Paulo: Makron Books, 1995.

SELEME, R. Métodos e tempos: racionalizando a produção de bens e serviços. Curitiba: Ibpex, 2009.

SLACK, N.; CHAMBERS, S.; JOHNSTON, R. Administração da produção, São Paulo: Atlas, 2. ed., 2002, 747 p.

SILVA, A. L. Desenvolvimento de um modelo de análise e projeto de layout industrial, em ambientes de alta variedade de peças, orientado pela Produção Enxuta. $244 \mathrm{f}$. Tese (Doutorado em Engenharia de Produção) - Universidade de São Carlos, São Paulo, 2009.

SILVA, A. L.; RENTES, A. F. Um modelo de projeto de layout para ambientes job shop com alta variedade de peças baseado nos conceitos da produção enxuta. Gestão e Produção, São Carlos, v. 19, n. 3, p. 531-541, 2012.

VIEIRA, A. C. G. Manual de Layout. Rio de Janeiro: Manuais CNI, 1979,19 p. 